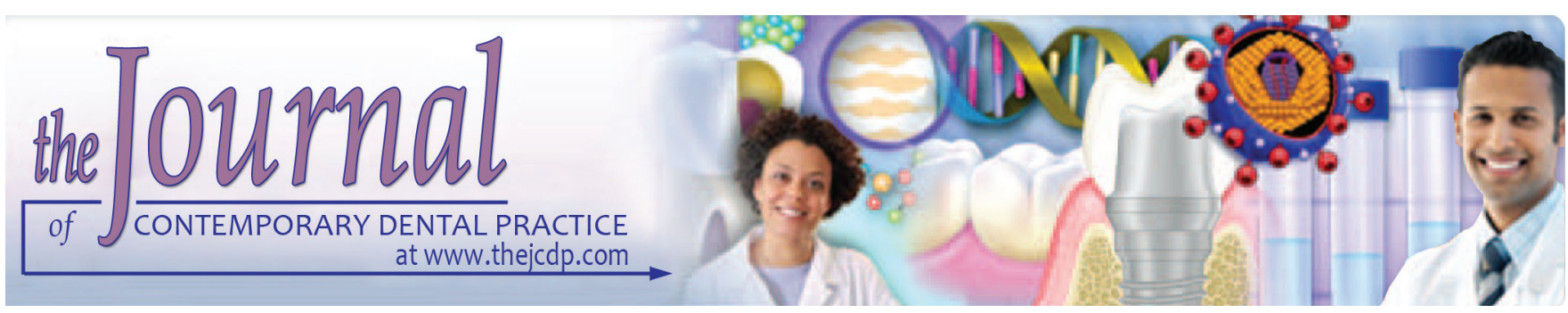

\title{
Awareness of Biomedical Waste Management among Dentists associated with Institutions and Private Practitioners of North India: A Comparative Study
}

${ }^{1}$ Malvika Raghuvanshi, ${ }^{2}$ Shruti Sinha, ${ }^{3}$ Gouse Mohiddin, ${ }^{4}$ Abikshyeet Panda, ${ }^{5}$ Kailash C Dash, ${ }^{6}$ Lipsa Bhuyan

\begin{abstract}
Aim: The present study aimed to obtain information about knowledge, execution, and attitude toward biomedical waste (BMW) and its management.

Materials and methods: In the present study, a self-administered closed-ended questionnaire was designed to conduct a crosssectional survey. It was distributed among 614 dentists (institution associated or private practitioners) in the cities of North India. The questionnaire comprised 36 questions regarding knowledge, execution, and attitude toward BMW and its management. Frequency distribution and chi-square test along with paired t-test were used to compare the data obtained between the private practitioners and institution-associated dentists.
\end{abstract}

Results: The study showed that $80 \%$ private practitioners were aware of the categories of BMW as compared with $100 \%$ of institution-associated dentists. However, $41 \%$ dentists associated with institution were disposing the chemical waste directly into sewer and a surprising high number of private practitioners were discarding directly without any treatment. Furthermore, regarding the mandatory maintenance of BMW records, $100 \%$ institution-associated respondents were aware, whereas only $6.5 \%$ private practitioners knew about it. Regarding BMW management not frequently being followed, $78 \%$ of private practitioners believed extra burden as the reason.

Conclusion: Most of the dentists had adequate knowledge regarding BMW policies and its management. Although it was being practiced in mostly all the institutes on a regular basis, the majority of private practitioners were not practicing it due to various reasons, such as financial burden, lack of availability of service, and poor attitude toward its management.

1,3-6Department of Oral Pathology, Kalinga Institute of Dental Sciences, Bhubaneswar, Odisha, India

${ }^{2}$ Department of Oral Pathology, Saraswati Dental College Lucknow, Uttar Pradesh, India

Corresponding Author: Malvika Raghuvanshi, Department of Oral Pathology, Kalinga Institute of Dental Sciences Bhubaneswar, Odisha, India, e-mail: drmalvikaraghuvanshi@ gmail.com
Clinical significance: There is a need to make it compulsory and organize training sessions to educate the dental personnel and to establish the importance of proper management.

Keywords: Biomedical waste, Hazardous waste, Infectious waste, Waste disposal.

How to cite this article: Raghuvanshi M, Sinha S, Mohiddin G, Panda A, Dash KC, Bhuyan L. Awareness of Biomedical Waste Management among Dentists associated with Institutions and Private Practitioners of North India: A Comparative Study. J Contemp Dent Pract 2018;19(3):273-277.

Source of support: Nil

Conflict of interest: None

\section{INTRODUCTION}

The Bio-Medical Waste (Management and Handling) Rules, 1998 published vide notification number S.O. 630 (E) dated July 20, 1998, by the Government of India in the erstwhile Ministry of Environment and Forests provided a regulatory framework for the management of BMW generated in the country. ${ }^{1,2}$ The term "biomedical waste" means any waste generated during the diagnosis, treatment, or immunization of human beings or animals or research activities pertaining thereto or in the production or testing of biological or in health camps, including the categories mentioned in Schedule I appended to these rules.,

Improper segregation and disposal of BMW and mixing it with municipal waste can result in the possible exposure of the health care workers, waste-handlers, waste-pickers, and also of the general public to deadly infections, such as acquired immunodeficiency syndrome, hepatitis B, etc. ${ }^{2,5-7}$ Dental practices generate huge amounts of BMW in the form of cotton, latex, plastic, glass, sharps, and extracted teeth and other materials which may be contaminated with blood and body fluids. ${ }^{8,9}$

Very few studies were conducted on awareness of BMW management procedures among dentists in India. 
However, no such study was done comparing dentists associated with the institution and private practitioners; hence, we planned to conduct the same in the cities of North India. The present study aimed to obtain information about knowledge, execution, and attitude toward BMW and its management. It also aimed to compare the above information between the dentists associated with institutions and private practitioners.

\section{MATERIALS AND METHODS}

The present study was done in various cities of North India. The study was conducted for a period of 4 months from January to April 2017. A total of 700 registered dentists were included in the study. However, out of these, only 614 dentists took part in the study [51\% Bachelor of Dental Surgery (BDS) and 49\% Master of Dental Surgery (MDS)], of which 293 (48\%) were associated with institutions and 321 (52\%) were private practitioners.

\section{Inclusion Criteria}

Only those dentists were selected in the study who were either doing private practice or associated with institutions.

\section{Exclusion Criteria}

Dentists associated with institutions as well as and having private setup were excluded from the study.

A full description of the study protocol was submitted to the ethical review committee of the institute; however, as there would be no pressure on the respondents to participate in the survey and their anonymity would be maintained, no formal ethical approval was necessary. Informed consent was given by each respondent included in the study. A self-administered questionnaire was designed consisting of 36 questions. It was divided into four categories, namely, general information, knowledge of rules, execution of rules, and attitude of the dentists toward BMW and its management. The dentists were approached personally or through e-mail. They were requested to fill the questionnaire and mail it back within a week's time. The data were thus collected and subjected to statistical analysis.

\section{Statistical Analysis}

Frequency distribution and chi-square test along with paired t-test were used to compare the data obtained between the private practitioners and institution-associated dentists.

\section{RESULTS}

A self-structured close-ended questionnaire was prepared and was distributed among 614 participants (51\% BDS and
Table 1: Frequency distribution according to educational qualification and association with institution and clinic

\begin{tabular}{ll}
\hline Educational qualification & $n(\%)$ \\
\hline BDS & $314(51)$ \\
MDS & $300(49)$ \\
Total & $614(100)$ \\
Association & \\
Institute & $293(48)$ \\
Clinic & $321(52)$ \\
\hline Total & $614(100)$ \\
\hline
\end{tabular}

49\% MDS), of which 293 (48\%) were associated with institutions and $321(52 \%)$ were private practitioners (Table 1$)$.

The study revealed only $52(8.5 \%)$ were not immunized against hepatitis or tetanus and 284 (46.3\%) were immunized for both.

A total of $289(89 \%)$ private practitioners reported that 0 to $2 \mathrm{~kg}$ per day of waste was generated and only $34(11 \%)$ reported 2 to $5 \mathrm{~kg}$ waste generation. All (100\%) institutional respondents reported $>5 \mathrm{~kg}$ waste generation every day.

Daily frequency of waste disposal was reported by 244 (83\%) institution-associated respondents and 175 (55\%) private practitioners.

A total of $339(55 \%)$ respondents said they were aware of rules laid down by government, and 275 (45\%) had no knowledge $(\mathrm{p}<0.001)$. About $280(96 \%)$ respondents associated with institution said there was BMW disposal committee and only 21 (7\%) clinic-associated respondents said they followed BMW disposal policy.

Awareness about categories was quite high, as 549 $(89 \%)$ respondents said they were aware of categories.

Regarding Bureau of Indian Standards of plastic bags, only $14 \%$ overall awareness was recorded, which was quite low. Only 18\% private practitioners and 9\% institution-associated dentists were aware about it.

Only 109 (18\%) respondents said they were aware that records and register could be inspected by government authorities. The knowledge was poor irrespective of association with institute or clinic.

About 76\% were not aware that untreated human anatomical waste (extracted teeth and unfixed biopsy tissues) and soiled waste should not be stored beyond 48 hours. Irrespective of association with institution or clinic, the knowledge was inadequate.

The knowledge was inadequate for both cytotoxic and biohazard symbol.

A total of 489 (80\%) respondents said they maintained a record of sterilization, and only 125 (20\%) said they do not maintain any record. Most of them, irrespective of educational qualification, maintained the records: 100\% institution-associated respondents said they maintained but only $61 \%$ private practitioners maintained the record. 
Awareness of Biomedical Waste Management among Dentists

Table 2: Frequency distribution for need for educational programs and CDE attended

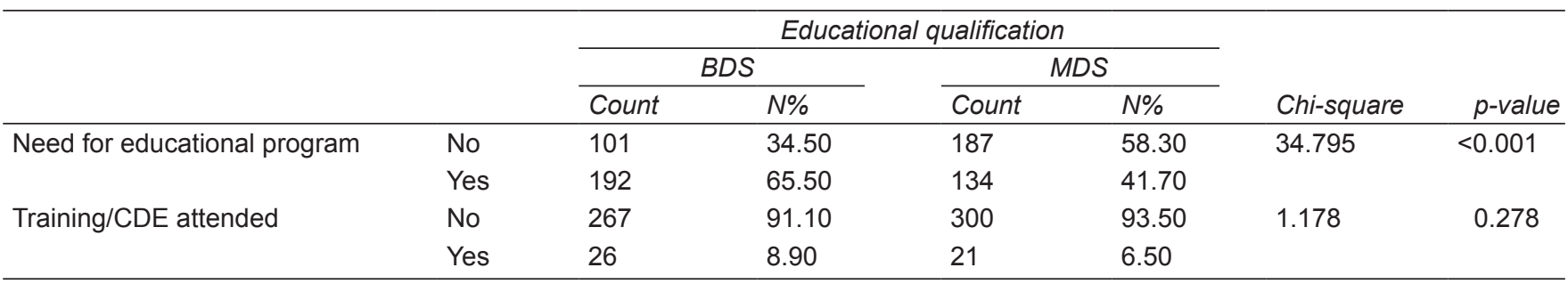

Surprisingly, 100\% clinical respondents did not maintain BMW management register and 91\% institutional respondents said they have BMW management register $(\mathrm{p}<0.001)$.

Institutions fared better in terms of safe, ventilated and secured location for storage, segregation of waste before disposal, trained staff, association with BMW treatment facility, and availability/use of color-coded bins (in contrast, only $54 \%$ private practitioners used these protocols).

A total of $293(100 \%)$ institutions had color-coded bags, but only 175 (54\%) private practitioners mentioned the use of recommended colored bags for disposal.

A total of $468(76 \%)$ respondents segregated waste before disposal, whereas 146 (24\%) did not segregate waste. All 293 (100\%) institution-associated respondents reported segregation of waste before disposal, whereas only 175 (54\%) private practitioners did so.

Regarding human anatomical waste, 298 (48\%) respondents were aware of its disposal in the yellow colored nonchlorinated plastic bags, whereas 316 (51\%) were not aware. About 136 (46\%) institution-associated dentists were aware of correct disposal bag and 162 (50\%) private practitioners gave correct answers.

Regarding sharps and needles, 513 (84\%) respondents gave correct answer, whereas $10(16 \%)$ dentists gave incorrect answers. Two hundred fifty-seven (88\%) institutionassociated dentists and $256(80 \%)$ private practitioners were aware of its disposal.

A total of $383(62 \%)$ respondents admitted that they directly dispose (developer/fixer) into sewer. Even 119 (41\%) institution-associated respondents and 264 $(82 \%)$ private practitioners were not aware of its correct disposal.

Only 143 (23\%) respondents stored lead foils/mercury separately before disposal. Only, 121 (42\%) institutionassociated respondents did separate storage, whereas $21(6 \%)$ private practitioners stored separately and then discarded.

Knowledge regarding expired medicines was very low among the dental personnel. Only 28\% knew the correct way of disposal. About $30 \%$ institution-associated respondents' and 25\% private practitioner's answers were correct.
A total of 285 (46\%) respondents said safe management of BMW was responsibility of government and 329 (54\%) respondents said it should be teamwork between government and dentists. A sharp contrast was seen as $75 \%$ institute-associated respondents said it should be teamwork, whereas $66 \%$ private practitioners said government should be responsible $(\mathrm{p}<0.001)$.

However, both groups were of same opinion that improper waste management is hazardous.

About $54 \%$ of institution-associated dentists said BMW management is not frequently followed due to lack of awareness, whereas $78 \%$ private practitioners quoted extra burden as the reason.

Need for educational program, training, and continuing dental education (CDE) among both groups is shown in Table 2.

\section{DISCUSSION}

The Bio-Medical Waste (Management and Handling) Rules, 1998, published by the Government of India under the Ministry of Environment and Forests, provides a regulatory framework for the management of BMW generated in the country.

Biomedical waste is an issue with serious implications. According to the World Health Organization, hospital waste yields 80 to $85 \%$ of nonhazardous waste and 15 to $20 \%$ of hazardous waste. The hazardous waste can be infectious (10\%) like sharps or noninfectious (5\%), such as chemical and pharmaceutical waste. ${ }^{5}$ Dental professionals are at a higher risk for acquiring cross-infection while treating patients, as most pathogens have been isolated from saliva. ${ }^{10-12}$ These pathogens including virulent strains of viruses and bacteria, which have hazardous effect on human health are involved in the segregation and disposal of BMW. ${ }^{4,13}$ Dental hospitals/clinics use instruments and materials that are directly exposed to blood and saliva. Furthermore, many chemicals, such as acrylics, impressions materials, and mercury are used in dentistry which if not properly discarded can lead to potential threat to the environment. ${ }^{14,15}$

Most of the survey studies carried out on awareness of BMW management procedures among dentists in India have been done on general and private dental practitioners 
and even lesser on those associated with dental institutions, which also contribute BMW in large quantity. However, the limitations of these studies were that participants may have been following the aforesaid guidelines of waste management protocol at one workplace and not at the other so keeping this in mind, we included dentists associated with only institutions or private clinics and excluded those associated with both. Furthermore, as no such study was reported comparing dentists associated with the institution and private practitioners, we planned to conduct the same in the cities of North India.

A self-administered questionnaire was used in our study as it allows us to gather large amount of data quickly and economically. Our study had 614 participants, which was higher than those of Arora et $\mathrm{al}^{16}$ and Singh et $\mathrm{al}^{8}$ study that had a sample size within the range of 100 to 200. Our study further divided respondents based on their association with the institution (48\%) or private clinic (52\%) which is not reported to have been done previously.

In our study, $89 \%$ private practitioners reported that 0 to $2 \mathrm{~kg}$ per day of waste is generated and only 34 (11\%) reported 2 to $5 \mathrm{~kg}$ waste generation. All (100\%) institutional respondents reported waste generation of $>5 \mathrm{~kg}$ every day, which was similar to the study conducted by Khandelwal et al. ${ }^{17}$

About $55 \%$ of respondents said they were aware of rules laid down by government which was in contrast to Sood and Sood ${ }^{2}$ and Kapoor et al, ${ }^{18}$ the difference could be attributed to the difference in the sample size.

Awareness about categories was quite high with 549 $(89 \%)$ respondents, which was in contrast to Singh et al. ${ }^{8}$ This can be due to the fact that institutional participants invariably had high response rate about awareness of categories.

Institutions fared better in terms of safe, ventilated, and secured location for storage, segregation of waste before disposal, trained staff, and association with BMW treatment facility, which was unique as no other study had collected separate data for institutions.

About $76 \%$ of respondents had knowledge of colorcoded bins which was similar to Narang et $\mathrm{al}^{6}$ and in contrast to Khandelwal et al, ${ }^{17}$ Kapoor et al, ${ }^{18}$ and Bala et al. ${ }^{15}$

About $76 \%$ of respondents segregated waste before disposal, whereas $24 \%$ did not segregate waste which was similar to Sudhakar and Chandrashekhar ${ }^{19}$ and Ogden et al. ${ }^{20}$

Regarding sharps and needles, $84 \%$ respondents gave correct answer which was similar to Sood and Sood. ${ }^{2}$

About $62 \%$ of respondents admitted that they directly dispose (developer / fixer) into sewer which was similar to Khandelwal et $\mathrm{al}^{17}$ and Singh et al. ${ }^{8}$ Developer solution does not contain silver, hence it can be diluted and put into sewer; whereas, on the contrary, fixer solution contains silver and if put into sewer it will increase the metal load in the sewer which is not allowed as per environmental protection rules. Spent fixer solution contains high amounts of silver, and thus should be stored separately and handed over to certified buyers.

About $23 \%$ of respondents stored lead foils / mercury separately before disposal, which was in contrast to Singh et al. ${ }^{8}$

About $72 \%$ incorrectly disposed of expired medicine, which was similar to Sood and Sood ${ }^{2}$ and Singh et al. ${ }^{8}$ Expired medicine is considered as cytotoxic waste and thus should be disposed of in a secured landfill.

About $54 \%$ of respondents said that it should be a teamwork between government and dentists, which was in contrast to Khandelwal et $\mathrm{al}^{17}$ and Kapoor et $\mathrm{al}^{18}$ as the majority of participants believed that it would add extra work and increase financial burden. Safe management of BMW comes across more of an attitude-related issue rather than the absence of or providing technology and facilities.

The present study showed that most of the dentists had adequate knowledge regarding BMW policies and its management. However, it was not satisfactory since there was considerable variation in practice and management of BMW. It was being practiced in mostly all the institutes on a regular basis, but the majority of private practitioners were not practicing it diligently. Lack of availability of service, lack of motivation, high cost factor, poor attitude, and failure to attend educational activities were major defects found among practitioners in the study.

\section{CONCLUSION}

Biomedical waste management is not only a social responsibility but a legal necessity as well. Care is required while disposing of BMW to protect and maintain the environment from contamination, and also to ensure the safety of those workers who come into direct contact with it. It should be included in the curriculum for medical, dental, and paramedical so that medical personnel understand the need and importance of segregation and disposal of BMW. Furthermore, it should be made compulsory for oral health care personnel to get their nontechnical and housekeeping staff trained in this field. Continuing dental education and training programs, workshops, and short courses on cross-infection and BMW management should be conducted to improve the knowledge of the health care personnel and to establish the importance of proper management.

\section{ACKNOWLEDGMENTS}

The authors acknowledge and thank all dentists for participating in the study. 


\section{REFERENCES}

1. Government of India. Biomedical Waste (Management and Handling) Rules. Extraordinary, Part II, Section 3, Subsection (ii). The Gazette of India, Notification 28. New Delhi: Government of India; 2016.

2. Sood AG, Sood A. Dental perspective on biomedical waste and mercury management: a knowledge, attitude, and practice survey. Indian J Dent Res 2011 May-Jun;22(3):371-375.

3. Government of India. Biomedical Waste (Management and Handling) Rules. 1998 Extraordinary, Part II, Section 3, Subsection (ii). The Gazette of India, No. 460. New Delhi: Government of India; 1998.

4. National Guidelines on Hospital Waste Management. Biomedical waste regulations. New Delhi: Ministry of Health and Family Welfare; 1998.

5. National AIDS Control Organization. Manual for Control of Hospital Associated Infections. Standard Operative Procedures. New Delhi: National AIDS control organization; 1999. pp. 50-66.

6. Narang R, Manchanda A, Singh S, Verma N, Padda S. Awareness of biomedical waste management among dental professionals and auxillary staff in Amritsar, India. Oral Health Dent Manag 2012 Dec;11(4):162-168.

7. Patil GV, Pokhrel K. Biomedical solid waste management in an Indian hospital: a case study. Waste Manag 2005 Feb;25(6):592-599.

8. Singh RD, Jurel SK, Tripathi S, Agrawal KK, Kumari R. Mercury and other biomedical waste management practices among dental practitioners in India. Biomed Res Int 2014 Aug;2014:272750.

9. Bates MN. Mercury amalgam dental fillings: an epidemiologic assessment. Int J Hyg Environ Health 2006 Jul;209(4):309-316.

10. Singh BP, Khan SA, Agrawal N, Siddharth R, Kumar L. Current biomedical waste management practices and crossinfection control procedures of dentists in India. Int Dent J 2012 Jun;62(3):111-116.
11. Mehta A, Gupta M, Upadhyaya N. Status of occupational hazards and their prevention among dental professionals in Chandigarh, India: a comprehensive questionnaire survey. Dent Res J (Isfahan) 2013 Jul-Aug;10(4):446-451.

12. Pandit NB, Mehta HK, Kartha GP, Choudhary SK. Management of bio-medical waste: awareness and practices in a district of Gujarat. Indian J Public Health 2005 Oct-Dec;49(4):245-247.

13. Prüss, A.; Giroult, E.; Rushbrook, P. Safe management of wastes from health-care activities. Geneva: World Health Organization; 1999.

14. Shah AF, Yousuf A, Jan SM, Batra M, Sidiq M, Baba IA. Feedback survey on awareness and management of biomedical waste among dental health care personnel in Kashmir, India. Int J Contemp Med Res 2016 Jul;3(7):2163-2167.

15. Bala S, Narwal A. Awareness of bio-medical waste management among hospital and dental college and hospital employees. A panoramic view. J Oral Health Community Dent 2013 Jan;7(1):1-7.

16. Arora R, Agrawal A, Singh D, Reddy J. Management of dental waste in private clinics in Chhattisgarh State, India - a cross sectional study. J Dent Med Sci 2014 Jan;13(1):53-56.

17. Khandelwal V, Khandelwal S, Thakur JS. Health care waste disposal among private dentist in an Indian city: it's time to act. Int J Infect Control 2013 Jun;9(2):1-5.

18. Kapoor D, Nirola A, Kapoor V, Gambhir RS. Knowledge and awareness regarding biomedical waste management in dental teaching institutions in India - a systematic review. J Clin Exp Dent 2014 Oct;6(4):e419-e424.

19. Sudhakar V, Chandrashekhar J. Dental health care waste disposal among dental practices in Bangalore city, India. Int Dent J 2008 Feb;5(1):51-54.

20. Ogden GR, Bahrami M, Shivarajasingam V, Phillips G. Dental student's knowledge and compliance in cross infection control procedures at UK dental hospital. Oral Dis 1997 Mar;3(1):25-30. 